\title{
Developing next-generation climate change scholars: the DISCCRS experience
}

\author{
Ronald B. Mitchell • C. Susan Weiler
}

Published online: 29 March 2011

(C) AESS 2011

\begin{abstract}
Addressing climate change successfully will require an interdisciplinary network of climate change scholars who can communicate effectively with scholars from other disciplines and with the many audiences beyond the ivory tower. Those scholars will need teamwork skills that foster sustained interdisciplinary collaborations and the specific professional skills and training needed for interdisciplinary scholars to navigate successfully in a disciplinary academic world. Yet, at present, our institutions of higher education are not providing these skills to new Ph.D.s. Most graduate students receive extensive disciplinary training but little, if any, training in doing interdisciplinary research, communicating effectively, or building their careers. The authors have developed DISCCRS-the Dissertations Initiative for the Advancement of Climate Change Research - to build this network of climate change scholars and to target these shortcomings in current training of climate change scholars. This article describes the institutional obstacles and disincentives that hinder the training of graduate students, and the career progress of faculty, interested in conducting interdisciplinary climate change research. The DISCCRS initiative's annual Symposia, Dissertation Registry, website, and weekly electronic
\end{abstract}

R. B. Mitchell $(\bowtie)$

Department of Political Science and Environmental Studies Program, University of Oregon,

Eugene, OR 97403-1284, USA

e-mail: rmitchel@uoregon.edu

URL: http:pages.uoregon.edu/rmitchel/

\section{S. Weiler}

Atmospheric and Geospace Sciences Division, Cross-Directorate and Interdisciplinary Programs, National Science Foundation, 4201 Wilson Boulevard,

Arlington, VA 22230, USA newsletter are described as ways to build an interdisciplinary network of scholars and to improve that network's communication, team building, and early-career development skills. DISCCRS has developed a model that can be used, in whole or in part, as more universities take up the challenge of developing the next generation of climate change scholars.

Keywords Climate change scholars · DISCCRS .

Interdisciplinary programs $\cdot$ Team building $\cdot$ Climate change

\section{Introduction}

How should we train the next generation of scholars to better address the problem of climate change? Addressing climate change will require scholars who couple new interdisciplinary knowledge and skills as well as team and communication skills with the continuing need for disciplinary knowledge and skills. Although most graduate programs do well at providing $\mathrm{PhDs}$ with deep disciplinary knowledge and skills, they do less well at providing them with the needed foundation for interdisciplinary work. Little has changed since Steve Schneider, to whom the present issue is dedicated, complained in 1995 of the failure of most academic institutions to foster interdisciplinary training in general and collaboration between natural and social scientists in particular (Schneider 1995, 9). Nations signed the United Nations Framework Convention on Climate Change in 1992, and climate change scholarship has grown exponentially since. But most scholars remain fundamentally disciplinary and have relatively little influence on public opinion, government policy makers, or economic and social decision makers. Our graduates increasingly need, and are demanding, skills so they can 
better contribute to global society's efforts to address climate change.

Interdisciplinary research is a critical tool for addressing climate change and other complex and challenging global environmental problems (Brown et al. 2010; Hartesveldt and Giordan 2008, 4; US National Academy of Sciences et al. 2005). Interdisciplinary programs, institutes, and centers have emerged to help society understand and address the problems of such coupled human and natural systems. But to ensure a larger future cohort of top-tier researchers who have the skills and desire to succeed in an interdisciplinary environment, it will be necessary to change dominant academic paradigms to better train graduate students in interdisciplinarity and to better promote their careers as faculty members and researchers. Climate change increases the urgency of fostering the development of interdisciplinary, collaborative climate change research and giving the next generation of scholars the skills to communicate effectively and work effectively in collaborative team settings.

Weiler developed several successful interdisciplinary initiatives for the aquatic and Earth sciences between 1993 and 2003, including the first cycle of the Dissertations Initiative for the Advancement of Climate Change Research (DISCCRS, pronounced "discourse"). Since the first DISCCRS Symposium, the authors have extended DISCCRS to give recent PhDs across the natural and social sciences the academic and professional skills and resources they need for successful interdisciplinary research careers related to climate change, impacts, and solutions. DISCCRS is built on two premises: (a) most new PhDs emerge from academic institutions with strong disciplinary training but few of the interdisciplinary skills crucial to climate change scholarship and (b) most new PhDs will take positions at academic or research institutions that present significant obstacles and disincentives to successful careers conducting interdisciplinary research on climate change. DISCCRS includes intensive week-long Symposia; a public website-http://disccrs.org/—with climate change information, professional-development resources, and a searchable online registry of dissertation abstracts (with which any $\mathrm{PhD}$ graduate may register); and a weekly electronic newsletter of climate news, resources, and interdisciplinary job announcements. We have designed these facets of the initiative to promote two central goals: establishing a collegial interdisciplinary network of climate change scholars and enhancing the early career development of the scholars in that network. Steve Schneider shared these goals and played an important role in DISCCRS, attending a workshop that contributed to the design of the Symposia and by serving as a Mentor at the third DISCCRS Symposium held in 2007.

Our experience with DISCCRS has taught us a great deal about what $\mathrm{PhDs}$ interested in doing interdisciplinary research on climate change need and want. We have designed and refined various components to address those needs and wants and to help interdisciplinary climate change scholars "jump-start" their careers. The agenda for the Symposia reflects interactions with a select group of scholars who have identified skills and training that they feel were lacking in their academic training. In what follows, we describe the challenges these scholars face and the ways that the DISCCRS initiative addresses them. Many of these components would work equally well-if not better - if deployed by universities seeking to promote the training of interdisciplinary students and the careers of interdisciplinary faculty, where the individual components could be extended from a few hours to a day, week, or semester, or spread over several years of undergraduate or graduate training. Although none of them are costly or difficult, very few institutions are yet doing them. We hope that scholars who have attended DISCCRS Symposia become "agents of change," taking steps at their home institutions to foster interdisciplinary climate research. We also hope this article will provide both specific suggestions and the necessary "nudge" to other scholars and administrators to implement similar ideas.

\section{Challenges to being an interdisciplinary scholar}

Climate change poses a deeply interdisciplinary policy problem. First, greenhouse gas emissions are driven by interactions among a complex set of cultural, social, political, psychological, and economic forces and institutions. Second, the Earth system's response to human and natural forcings are a product of interactions among a complex set of chemical, physical, and biological processes. Third, the impacts human communities experience from - and their vulnerability and resilience to - the Earth system's response will depend on interactions among the same forces and institutions that drive emissions. And, finally, the responses of human communities to climate change will also be influenced by interactions among those same forces and institutions. In short, climate change is the quintessential "coupled human and natural system" (Liu et al. 2007; see also US Climate Change Science Program 2003, 21; US National Science Foundation 2000).

Understanding most aspects of climate change requires deep knowledge of numerous disciplines, including natural sciences, social sciences, and humanities. But it also requires "interdisciplinary conversance," i.e., an understanding of the interactions between the forces and processes that each discipline studies (Hartesveldt and Giordan 2008, 2). It requires interdisciplinarity rather than multidisciplinarity. Schneider defined interdisciplinarity as "individuals or teams of diverse specialists which learn 
enough-individually or collectively_about a range of relevant disciplinary methods and content to combine such multidisciplinary knowledge into an original synthesis that helps to raise understanding of systems phenomena or to solve a real problem," contrasting it with multidisciplinarity, which is defined as "specialists from various disciplines applying their respective disciplinary paradigms and methods in parallel on restricted aspects of some broad systems problem" (Schneider 1995, 9; see also Miller 1982; Wallace 2010; US National Academy of Sciences et al. 2005). Schneider's career reflected his unmatched dedication to conducting his own interdisciplinary research and to promoting the research and careers of others doing the same, particularly early-career scholars. But interdisciplinarity is more often a trait of groups than of individuals. It emerges from "expert teams" through successful communication and collaboration. Unfortunately, current curricula rarely provide the collaborative teamwork and communication skills needed to identify and understand synergies and interactions across disciplinary boundaries or to educate others and inform those "beyond the ivory tower" about how "to solve a real problem."

The desire to understand climate change is not merely "academic," however. Like many interdisciplinary problems, researchers are driven by the desire to help solve complex social problems (Paytan and Zoback 2007, 950). For example, a recent American Psychological Association Task Force's final section was titled "How can psychologists assist in limiting climate change?" (Swim et al. 2009). In 1998, Jane Lubchenco called scientists to take up challenges such as climate change and to "facilitate the investigation of complex, disciplinary problems that span multiple spatial and temporal scales; to encourage interagency and international cooperation on societal problems; and to construct more effective bridges between policy, management, and science as well as between the public and private sectors" (Lubchenco 1998). Such efforts are likely to be ineffective, however, unless specialists learn how to communicate effectively to a broader audience. Most scientists speak to public audiences, policy makers, and school children in the same ways they speak to their colleagues. Very few are encouraged, or learn how, to communicate effectively to students, educators, and the public; to the media; to stakeholders and interest groups; or to resource managers, policy makers, or other decision makers. Several excellent communication training programs exist, including the Aldo Leopold Fellowship (http:// leopoldleadership.stanford.edu/) and SeaWeb (http://www. seaweb.org/home.php). The National Science Foundation (NSF)-sponsored Centers for Ocean Sciences Education Excellence (http://www.cosee.net/) promote partnerships between research scientists and educators, disseminate best practices in ocean sciences education, and promote ocean education as a charismatic, interdisciplinary vehicle for creating a more scientifically literate workforce and citizenry. Other organizations-e.g., Climate Central (http://www.climatecentral.org/) and the Pew Center on Global Climate Change (http://www.pewclimate.org/) have taken up the challenge of communicating climate science more effectively to the public. Yet, most doctoral students graduate with few of the skills needed to do that job themselves.

The institutional structures that lead to less-thanadequate interdisciplinary training for climate change $\mathrm{PhDs}$ are matched by obstacles and disincentives to their subsequent career development. "The scientific community recognizes the importance of interdisciplinary research. But institutions have not yet caught up with ways to reward good examples of it. In fact, interdisciplinary research in academia often faces discouraging barriers" (Paytan and Zoback 2007, 950). Universities and funding agencies create barriers and disincentives to interdisciplinary research, including "structures and policies that place disciplinary research and training in conflict with interdisciplinary research and training or that do not support the infrastructure required for interdisciplinary success" (Hartesveldt and Giordan 2008, 22; US National Science Foundation 2000, 37). Despite innovations at some institutions, tenure at most universities still depends largely on demonstrating excellence within a narrowly defined discipline (Paytan and Zoback 2007, 950; Hartesveldt and Giordan 2008, 2).

These obstacles have parallels in the funding world. The NSF, the National Aeronautics and Space Administration (NASA), and other federal agencies have made commendable progress in developing innovative interdisciplinary initiatives such as those on biocomplexity and coupled human and natural systems, and NSF's Integrative Graduate Education and Research Traineeship (IGERT) program (http://www.nsf. gov/funding/pgm_summ.jsp?pims_id=12759). Yet, federal funding agencies continue to "fall short," with funding allocations that still favor standing disciplinary directorates and programs over interdisciplinary cross-directorate initiatives and that rely on external reviewers and review panels whose members are not always fully "receptive to and conversant with interdisciplinary research" (Hartesveldt and Giordan 2008, 2).

Publishing interdisciplinary work also is difficult. Most journals have a disciplinary mandate. Interdisciplinary journals face problems in attracting high-quality articles, identifying reviewers committed to applying rigorous but interdisciplinary criteria, and building a readership base that builds the journal's reputation by citing published articles. Good interdisciplinary articles may lose in the competition for page space. Given that tenure, promotion, and grants depend on publishing in the "top journals in one's field," 
such obstacles reinforce the challenges that interdisciplinary scholars face. And, in many fields, the co-authorship that collaboration necessarily entails (and issues of authorship order) can raise questions among external reviewers and administrators during tenure and promotion decisions. If publishing interdisciplinary work is both more difficult and less rewarded, scholars have strong incentives to focus on disciplinary research and publication.

Helping the next generation of scholars contribute to our understanding of, and responses to, climate change requires that we address these institutional shortcomings.

\section{The DISCCRS experience}

The DISCCRS initiative has four main objectives:

- To develop an interdisciplinary network of climate change scholars;

- To help scholars communicate effectively both with other scholars in the "ivory tower" and with the many audiences beyond the ivory tower;

- To provide the teamwork skills necessary to successful interdisciplinary collaborations; and

- To offer professional development skills to interdisciplinary scholars to navigate more successfully in a disciplinary academic world.

DISCCRS has built on previous initiatives organized to increase interdisciplinary interactions among new scholars from different natural science disciplines and to foster their early career development. DISCCRS seeks to promote such interactions across a broader range of disciplines, particularly across the natural/social science divide. We also welcome educators, mathematicians, engineers, and humanities scholars.

The DISCCRS initiative has four components. The centerpiece is an annual, week-long, Symposium at which 30 to 40 recent $\mathrm{PhDs}$ working on climate change interact with and learn from peers and carefully selected academic Mentors, funding agency representatives, and trainers. These "Symposium Scholars" are selected through a rigorous application process. They emerge from the Symposia with a highly interdisciplinary collegial peer network, a greater understanding of other disciplinary perspectives concerned with climate change, the teamwork skills needed to work collaboratively, the communication skills needed within those groups and when talking to and writing for other audiences, and the professional skills needed to succeed in interdisciplinary research. The DISCCRS Dissertation Registry, initiated in 2002, is a unique database of over 1,300 abstracts of doctoral dissertations focused on climate change completed since 1996, in disciplines ranging across the natural and social science disciplines. The Registry is part of the DISCCRS website (http://disccrs.org/), which also contains extensive climate change information and professional-development resources. We produce a weekly e-newsletter that delivers time-sensitive information on climate news, resources, and interdisciplinary job announcements. The rest of this article describes these components in more detail, focusing on the annual Symposia.

\section{Developing an interdisciplinary network of climate change scholars}

There will always be some interdisciplinary individuals who, like Steve Schneider, have deep knowledge of several fields and the ability to integrate across them. Most interdisciplinary work, however, emerges from collaborations among disciplinary scholars committed to answering interdisciplinary questions. We believe that such collaborations are more likely among those who are part of an interdisciplinary network in which participants gain substantive knowledge about other fields, come to better understand the different perspectives and methods of other fields, and, perhaps most importantly, build collaborations around mutually interesting questions that none of them believes they can answer alone.

Sponsorship from ten academic societies representing a range of disciplines enables us to reach an immensely interdisciplinary audience (see http://disccrs.org/ for a list of sponsoring societies). Advertising and dissemination strategies ensure that the DISCCRS network is also international (in terms of nationality, country of residence, and country of $\mathrm{PhD}$ ) and includes traditionally underrepresented groups, including women and minorities. The DISCCRS network is intended to facilitate identification of collaborators who can bring different and unexpected knowledge and insights to a research proposal and to research findings.

The DISCCRS website, dissertation registry, and enewsletter provide the infrastructure for such a network. The website and dissertation registry attract new scholars to the network and make them aware of cutting-edge climate change scholarship from numerous disciplines. The website and registry also make these new scholars aware of the many others who, like themselves, want to do interdisciplinary work on climate change. The weekly e-newsletter exposes over 2,000 subscribers to climate research news from disciplines that they would be unlikely to come across otherwise. By searching the registry's abstracts, people can identify colleagues and potential collaborators from other disciplines working on related aspects of climate change.

The week-long Symposia help scholars develop particularly strong relationships that are the core of the DISCCRS network. Over 170 Symposium Scholars have taken part in 
five Symposia between 2003 and 2010. During the first day and a half of each Symposium, each Scholar is given 7 minutes to present his or her research to the Scholars, Mentors, funding representatives, and trainers. These presentations get people "up to speed" on an amazing amount of cutting-edge climate change scholarship from numerous disciplines. Few professional conferences have presentations on climate change that reflect such a wide array of disciplines. Beyond transferring substantive knowledge, the presentations expose audience members to new questions, perspectives, and methods.

Six to ten respected climate change scholars attend each DISCCRS Symposium as Mentors. We select Mentors with reputations for excellent interdisciplinary climate change research who are also committed to-and skilled atmentoring the next generation of research scientists. Mentors include senior and mid-career scholars from the social and natural sciences. Each Mentor makes a keynote presentation that exposes Scholars to high-level thinking about the climate change problem, the breadth of disciplinary perspectives and the importance of interdisciplinary thinking, and effective presentational and communication styles. During the week, a panel of Mentors discusses the benefits, challenges, and tried-and-true strategies of getting successful interdisciplinarity collaborations funded, completed, and published. Their stature and experience affirm both the possibility and value of conducting an interdisciplinary research career successfully.

Each Symposium ends with an "interdisciplinary collaborative research" exercise. Teams of six to ten Scholars are either identified by the Organizers or allowed to develop organically, but in either case are expected to be as interdisciplinary as possible with respect to disciplinary expertise, gender, geographic and institutional representation, and other factors. Each team must develop an initial interdisciplinary proposal that takes advantage of the interests, knowledge, and skills of the team's diverse specialists. The exercise, usually limited to 6 hours, is too brief for full development of proposals, but the experience gives Scholars a sense of interdisciplinary research, including its surprising challenges and insights and the ways in which it differs from their training as specialists. Although the exercise is contrived and no actual research projects are expected, teams at each Symposium have proposed impressively coherent and compelling research. Several have continued their collaborations, developing a portion of their proposal more fully, conducting research together, or co-authoring articles on more limited sets of common interests (see, for example, Mignone et al. 2009).

The informal interactions at the Symposia are as crucial to developing a true collegial network of climate change scientists as the more formal agenda. Holding the Symposia at retreat-style and setting aside substantial time in the agenda foster informal interactions among Scholars, mentors, funding agency representatives, and trainers, including individual meetings, small group discussions and conversations at meals, and poster sessions. The program creates an atmosphere in which all participants recognize the value of minimizing the intrusions of cellphones, the internet, and work and maximizing the time for interactions with the other climate change scholars. This makes for an intense week, with academic and professional discussions starting before the first cup of coffee and continuing well into the night.

Developing an interdisciplinary network starts by simply creating a forum, like the DISCCRS Symposia, for interaction among scholars interested in learning from and working on climate change with those from other disciplines. Such forums for interdisciplinary interaction be, and are being, adopted at many universities. Interdisciplinary environmental seminars are held at many universities, with both local and out-of-town scholars making presentations. When senior scholars establish the norm of regular attendance, new scholars and graduate students follow. Such seminars foster the substantive transfer of knowledge, but they also promote collaborations as serendipitous ideas emerge from pre- and post-seminar conversations, conversations that only arise within a forum for interaction with those outside one's own department.

\section{Improving the ability to communicate effectively}

Effective communication is the cornerstone of interdisciplinary work. To conduct such research at all requires that scholars communicate effectively with those in other disciplines. To conduct it to promote a well-informed public and contribute to societal efforts to address climate change requires that scholars communicate effectively with a range of audiences, including the lay public, school children, stakeholders, businesspeople, government employees, and policy makers. Our experience with DISCCRS has confirmed the central role that communication plays in effective interdisciplinary research collaborations.

Promoting interdisciplinary research involves helping disciplinary specialists realize the importance and relevance of the knowledge of other disciplines. The specificity of the questions that most doctoral dissertations address often hinders development of a broader perspective in which those questions are seen as important but partial answers to larger-scale questions. Effective communication across disciplines helps new scholars develop "different ways of conceptualizing problems [and] an openness and respect for other disciplines," skills central to interdisciplinary research (US National Science Foundation 2000, 30). But cross- 
disciplinary communication is not easy (Hassol 2008). Much disciplinary research engages complex and complicated phenomena that often are difficult for those without relevant disciplinary training to comprehend. Thus, the details of climate-related biogeochemical interactions between the earth's atmosphere and oceans may be as challenging for a political scientist to comprehend as are the details of international climate change negotiations for a biogeochemist. Likewise, the jargon and buzzwords that foster efficient communication within a discipline often impair communication across disciplines. Words used in one field may be unknown in others-e.g., "phenology" may be unknown to economists just as "externality" may be unknown to biologists (Hassol 2008). And the meaning of words in two fields may be all-but-unrelated. Thus, "climate regime" refers to a period of relatively similar climatic conditions to natural scientists but refers to the UN Framework Convention on Climate Change and related institutions for most social scientists.

Effective communication across disciplines also requires understanding of and respect for methodological and epistemological differences. Disciplines vary significantly in how they judge the validity and credibility of findings. The experiments used in many natural science disciplines are unavailable in many social science disciplines. Quantitative findings are granted considerable credibility in some fields, but not others. Effective interdisciplinary collaborations only occur when those involved overcome their biases about what constitutes "evidence" and the "proper" way to analyze available evidence.

Because climate change poses societal problems as well as scholarly questions, scholars must also know how to communicate effectively beyond the ivory tower. "Scientists ... have little training in how to communicate to broad audiences and ... until recently, most scientists have not been particularly anxious to take the time to communicate their message broadly" (Oreskes 2007, 77; Carrada 2006, 28). The fact that most decision makers and the public are not well versed in climate science, or even in science generally, also creates challenges. Although scholars rightly highlight scientific uncertainties and do not recount "what we know" at scientific meetings, using such a strategy with decision makers and the public creates the perception that we know very little about climate change and that we are uncertain about what we do know. Likewise, scientists frequently use terms that are readily understood by other climate change researchers but are often not understood or mean different things to lay audiences (Hassol 2008).

Because communication is so important when talking to other academics or beyond the ivory tower, we stress communication throughout the Symposium, and we have specifically designed several DISCCR components to improve the Symposium Scholars' abilities to communicate to those in other disciplines and to nonscientists. Communication training begins with the requirement that each Scholar's oral presentation of his/her dissertation findings be limited to 7 minutes and be addressed to a non-specialist audience. The time constraints and the audience being addressed push Symposium Scholars to identify their key "take-away" points and to hone and simplify their message so those with no previous background can understand it. To enhance communication skills, each Scholar receives feedback on his/her presentation from one other Scholar and one Mentor. This helps them identify their own strengths and weaknesses and learn from the strengths and weaknesses of others. Equally, it gives them practice at providing constructive but honest criticism to others, which is crucial to the long-term success of interdisciplinary collaborations. The 6 hour collaborative research exercise at the end of the week provides an opportunity to practiceand to experience the obstacles to-communication across disciplines. The plenary presentations of team proposals give them additional practice at communicating to a broader audience.

At each Symposium, we have experts lecture on communication skills and conduct training exercises. Climate change communication experts have included Susan Hassol (Climate Communication), Bud Ward (Yale Forum on Climate Change and the Media), Susanne Moser (Susanne Moser Research and Consulting), Lisa Dilling (University of Colorado), and Ashley Simons (SeaWeb). They have identified challenges to and strategies for effective communication with decision makers, students, and the public. Some have highlighted knowing your audience, avoiding jargon, highlighting what we know, repeating key points in simple and memorable ways, using imagery and metaphor, and using simple, unexpected, concrete, credible, and emotional stories (Moser and Dilling 2007; Heath and Heath 2006). Others have noted that truly effective communication requires "co-production" of knowledge, with scholars and the decision makers, resource managers, and stakeholders engaging in ongoing dialogue about interests, science, and potential policies (Jasanoff 2004; Lemos and Morehouse 2005). At the third DISCCRS Symposium, Steve Schneider gave a public lecture on climate change that allowed Scholars to see a true professional at communication "in action." Other Mentors have described their own successful-and sometimes amusingly unsuccessful-experience working with the media. Hands-on communication exercises at each Symposium have given Scholars practice at crafting their messages by using SeaWeb's "message box," videotaping mock newspaper interviews, holding press conferences, and writing news releases and op-eds. Our webpage includes Powerpoint presentations on these topics from the most recent Symposia (see http://disccrs.org/presentations), as 
well as links to materials used at earlier Symposia (see http://disccrs.org/career). Steve Schneider gave a powerful presentation entitled "The Right Stuff: Perspectives on Building a Successful Interdisciplinary Career" at a workshop that helped design the DISCCRS initiative (see http://disccrs. org/files/Schneider_RightStuff_2003.pdf).

\section{Team building}

Weiler has included the teaching of team-building skills in her interdisciplinary symposia since 1997 and has recently advocated it as a requisite for basic "survival training." A recent NSF report also noted that "teamwork skills are a necessity" for interdisciplinary work and noted that graduate students are still rarely trained in them (Hartesveldt and Giordan 2008, 15). Interdisciplinary research teams often bridge institutions, disciplines, cultures, and personality types. Interpersonal, team-building, leadership, and administrative skills are imperative. Precisely because interdisciplinarity is a trait of groups rather than individuals, team training can fall victim to the many obstacles that threaten its inclusion in the academic curriculum of undergraduate and graduate students. Training in these skills is routinely provided in the for-profit sector where innovation and efficiency are highly valued. Whether scholars who are part of a collaboration prioritize the project, stay engaged, and contribute their best research on time depends as much on teamwork skills as on the intellectual substance of the research. Teamwork requires "soft skills"- e.g., facilitating a meeting, understanding personality types, and developing emotional intelligencethat are rarely discussed, let alone taught, in academic settings (Hartesveldt and Giordan 2008, 15)

At each Symposium, we focus on how the selected Scholars can build and maintain interdisciplinary collaborations. Mentors discuss their successful and unsuccessful collaborations, highlighting the excitement and pleasures of such efforts while pointing out how difficulties such as personality differences and "bad dynamics" can cause such efforts to founder. Christina Olex (The Point), a corporate trainer with extensive expertise in team development, has worked with Weiler since 1997 to incorporate team skills into the training of recent interdisciplinary Ph.D. graduates. Evaluations from more than ten symposia organized by Weiler that have included team training have demonstrated consistently that new Scholars both enjoy and benefit from explicit training in team-building and facilitation skills.

The DISCCRS team training generally begins with a session that highlights the value of understanding "personality types" (Jung 1971/1923) in managing professional relationships and in building an "expert team" rather than a "team of experts." Before the Symposium, each Scholar identifies his/her personality type using a survey based on the work of Carl Jung and the Myers-Briggs typology (Myers et al. 2003). Emphasis is placed on differences in how people with different personality types act and react to a given situation and how these differences influence group dynamics. People differ in their preferences regarding taking in and processing information and making decisions, and these preferences interact with each other. Taking account of these differences can help Scholars in interdisciplinary collaborations, departmental interactions, lab settings, and small meetings, thereby helping them achieve their objectives with less conflict. For example, giving "introverts" time to think about a problem before a meeting allows them to make more thoughtful contributions, allows others to benefit from and value those contributions, and, therefore, keeps them more engaged in the collaborative enterprise (Laney 2002; Berens et al. 1999). The "personality type" exercise creates a novel experience for most participants that prompts considerable informal discussion and serves as a "bonding experience" that catalyzes the DISCCRS peer network. Analysis of the data on personality type of the DISCCRS Scholars reveals significant differences between Scholars' personality types and those of the general public, which has implications for team building as well as for effective communication strategies.

The team training sessions also teach facilitation skills and the importance of understanding productive and counterproductive group dynamics. This includes reviewing the difference between facilitating and leading a meeting; the need to establish group goals and ground rules and to engage and value contributions from all participants; and the value of assigning roles of facilitator, timekeeper, notetaker, contributor, and reporter. We have used a range of tools - from brainstorming and evaluating the group process midstream ("plus/deltas") to giving feedback and dealing with difficult people - that help meetings produce substantively better results faster and with greater participant satisfaction (Tropman 2003; Townsend and Donovan 2009). We hold this training early in the week so Scholars can use the skills in small group activities throughout the week. These skills help in mentoring and advising students, managing labs, or devising and conducting interdisciplinary research projects.

\section{Professional development}

The fourth major DISCCRS goal is to foster the professional development of new climate change scholars. Early career academics face the challenges of applying for jobs, negotiating a contract, getting hired, applying for grants, publishing, and, ultimately, receiving tenure or other forms of professional advancement. These issues pose unique and 
particularly daunting challenges for those committed to interdisciplinary research. Where does one find interdisciplinary climate change job listings? How should one negotiate a joint position between a disciplinary department and an environmental studies program? Who funds interdisciplinary research and what do successful collaborative proposals to those institutions look like? What are the best outlets for co-authored interdisciplinary research on climate change, and how does one ensure it "counts" at promotion time? How does one balance family and work life, when success in an interdisciplinary career may require more time and travel than normal for an assistant professor? These questions are anxiety-inducing, and our first step in fostering professional development is simply to address them. Each weekly DISCCRS e-newsletter includes dozens of climate change job listings from a range of disciplines and also highlights new resources for professional development in addition to those listed on the DISCCRS website (see http://disccrs.org/).

The Symposia provide numerous opportunities to discuss these issues. They regularly arise over meals and during other informal discussions. In response to participant requests, we have held an evening roundtable at which those with new jobs can discuss their job-hunting and negotiating experiences, and those looking for jobs or negotiating offers can raise questions. Each Symposium, a Mentor panel on interdisciplinarity has surveyed Mentors' different answers to balancing interdisciplinary research with the disciplinary research needed to earn tenure. This panel always prompts active discussion of how to get published, how to address collaborative authorship, what journals to publish in, and how to answer those questions in ways that most enhance one's chances for tenure. Each Symposium has included Mentors and Scholars with experience in "non-traditional" jobs in think tanks, nonprofit organizations, corporations, or consulting firms, experience that demonstrates the viability of alternative career opportunities. Mentors also have described how to "get involved"-whether with the IPCC, with NSF and NASA reviews, with policy makers, or with public education - in ways that foster rather than hinder one's career trajectory. At each Symposium, some Scholars have taken up the problem of balancing work and family, and several Symposia have included dual-career couples (including Steve Schneider and Terry Root at the 2007 DISCCRS Symposium) who have shared generously and openly their own efforts to balance work and family.

Each Symposium pays particular attention to funding of interdisciplinary research. Representatives from the agencies that have funded DISCCRS (currently NSF and NASA) have described their agencies, the particular programs and initiatives they have for interdisciplinary and collaborative climate change research, and their agency's proposal review process. We encourage Scholars to volunteer to participate in agency proposal review as an important part of community service, and as an excellent way of learning more about proposal writing. We follow these presentations with a panel discussion of agency representatives and Mentors to discuss both the process for developing good collaborative proposals and the criteria that distinguish successful proposals.

\section{Conclusion}

At the most general level, the DISCCRS initiative - the Symposia, but also the website, the e-newsletter, and the dissertation registry-provides forums through which Scholars are exposed to the implicit but important message that, despite its costs and risks, interdisciplinary research is important, valued, exciting, and rewarding, and that there is a thriving community of other scholars (and funding agencies) committed to doing such research throughout their careers. It also provides some very basic modules that can help catalyze individual and institutional change. We hope that others will find the DISCCRS features worth emulating.

The real solution to producing scholars who understand and can contribute to the resolution of the climate change problem will require that institutions remove the obstacles and disincentives described above. The DISCCRS initiative is making a contribution but it, necessarily, can play only a small role. We need to revise existing graduate programs, develop new ones, establish additional training programs, and make a range of other changes in order to develop a cohort of climate change scholars that is large enough and has the skills to answer the numerous complex and interdisciplinary questions that climate change poses. Some universities have already engaged this challenge and are training their students to be "interdisciplinarians." There is also much value in promoting specific interdisciplinary collaborations, e.g., by providing training opportunities like NSF's IGERT Program, that expose students to the pleasures, benefits, and challenges of interdisciplinary research. Yet, before such institutional change occurs, programs like DISCCRS can improve the ability of the next generation of scholars to understand and contribute to resolving climate change and can identify effective models that institutions can adopt.

DISCCRS has developed a model-involving week-long Symposia, a website, a weekly e-newsletter, and a registry of climate change dissertation abstracts - that can be used, in whole or in part, as more universities take up the challenge of developing the next generation of climate change scholars. Individual faculty members can host oneoff training sessions on "the interdisciplinary job search" or 
"getting interdisciplinary research funded." A small group of faculty can initiate a monthly interdisciplinary brown bag seminar on climate change that intersperses professional development presentations with substantive lectures. Daylong workshops or capstone experiences for climate change graduates can be designed using some of the components delineated above. The most important goal is to create opportunities for interdisciplinary scholars, both graduate students and faculty, to meet each other, exchange substantive knowledge, discuss the pleasures and struggles of interdisciplinary climate change research, and learn and practice the communication, team-building, and professional development skills they will need. At some schools, there may be sufficient institutional support to develop a weekend or even week-long DISCCRS-style retreat for graduate students working on climate change, regardless of department. None of the components of the DISCCRS initiative are difficult or expensive, and any could be expanded from the few hours that DISCCRS devotes to a theme to anything between those few hours and a 5-year $\mathrm{PhD}$ program. Such efforts are important steps, though only first steps, toward the deeper institutional changes that have been identified by numerous national reports. Developing institutions of higher education that train scholars for-and reward-interdisciplinary research on climate change and other complex interdisciplinary problems is a long-term task. The need exists for programs that foster interdisciplinary networks of climate change scholars and that provide those scholars with the communication, teamwork, and career development skills they need to contribute in meaningful ways over the course of their careers to understanding and addressing climate change.

\section{References}

Berens LV, Cooper SA, Ernst LK, Martin CR, Myers S, Nardi D, Pearman RR, Segal M, Smith MA (eds) (1999) Quick guide to the 16 personality types in organizations: understanding personality differences in the workplace. Telos Publications, Huntington Beach

Brown VA, Harris JA, Russell JY (eds) (2010) Tackling wicked problems through the transdisciplinary imagination. Earthscan, Washington

Carrada G (2006) A scientist's survival kit: communicating science. Office for Official Publications of the European Communities, Luxembourg

US Climate Change Science Program (2003) Vision for the program and highlights of the Scientific Strategic Plan. A report by the Climate Change Science Program and the Subcommittee on Global Change Research. http://www.climatescience.gov/Library/stratplan2003/vi sion/ccsp-vision.pdf. Accessed 8 Oct 2008

Hartesveldt CV, Giordan J (2008) Impact of transformative interdisciplinary research and graduate education on academic institutions. NSF Workshop Report. National Science Foundation,
Education and Human Resources Directorate, Division of Graduate Education, Integrative Graduate Education and Research Traineeship (IGERT) Program, Washington, DC

Hassol SJ (2008) Improving how scientists communicate about climate change. Eos 89(11):106-107

Heath C, Heath D (2006) Made to stick: why some ideas survive and some die. Random House, New York

Jasanoff S (ed) (2004) States of knowledge: the co-production of science and social order. Routledge, New York

Jung CG (1971) Psychological types. Princeton University Press, Princeton, 1923, 1st edn

Laney MO (2002) The introvert advantage: how to thrive in an extrovert world. Workman Pub, New York

Lemos MC, Morehouse BJ (2005) The co-production of science and policy in integrated climate assessments. Glob Environ Change 15:57-68

Liu J, Dietz T, Carpenter SR, Folke C, Alberti M, Redman CL, Schneider SH, Ostrom E, Pell AN, Lubchenco J, Taylor WW, Ouyang Z, Deadman P, Kratz T, Provencher W (2007) Coupled human and natural systems. Ambio 36(8):639-649

Lubchenco J (1998) Entering the century of the environment: a new social contract for science. Science 279:491-497

Mignone BK, Hurteau MD, Chen Y, Sohngen B (2009) Carbon offsets, reversal risk and US climate policy. Carbon Balance Manage 4(3):1-6

Miller RC (1982) Varieties of interdisciplinary approaches in the social sciences. Issues Integr Stud 1:1-37

Moser SC, Dilling L (eds) (2007) Creating a climate for change: communicating climate change and facilitating social change. Cambridge University Press, Cambridge

Myers IG, McCaullley MB, Quenk NL, Hammer AL (2003) MBTI manual: a guide to the development and use of the Myers-Briggs type indicator ( 3 rd edn). CPP, Palo Alto

Oreskes N (2007) The scientific consensus on climate change: how do we know we're not wrong? In: DiMento JFC, Doughman P (eds) Climate change. MIT Press, Cambridge, pp 65-99

Paytan A, Zoback ML (2007) Crossing boundaries, hitting barriers: interdisciplinary research may be lauded, but it's not yet rewarded. Nature 445:950

Schneider SH (1995) Evolutionary organizational models for interdisciplinary research and teaching of global environmental change. In: Waddington DJ (ed) Global environmental change in science: education and training. Springer in cooperation with NATO Scientific Affairs Division, Heidelberg

Swim J, Clayton S, Doherty T, Gifford R, Howard G, Reser J, Stern P, Weber E (2009) Psychology and global climate change: addressing a multi-faceted phenomenon and set of challenges (a report by the American Psychological Association's Task Force on the Interface between Psychology and Global Climate Change). American Psychological Association, Washington

Townsend J, Donovan P (2009) The facilitator's pocketbook (2nd edn). Management Pocketbooks, Ltd., Alresford

Tropman JE (2003) Making meetings work: achieving high quality group decisions, 2nd edn. Sage Publications, Thousand Oaks

US National Academy of Sciences, Committee on Facilitating Interdisciplinary Research, Committee on Science Engineering and Public Policy (U.S.) (2005) Facilitating interdisciplinary research. The National Academies Press, Washington

US National Science Foundation (2000) Environmental science and engineering for the 21 st century: the role of the National Science Foundation. US National Science Foundation, Washington

Wallace RL (2010) A very brief introduction to interdisciplinarity. Environmental Studies Program, Ursinus College, Collegeville, PA 